\title{
Investigation of Nitrogen-Doping Influence on the Electrocatalytic Activity of Graphene in Alkaline Oxygen Reduction Reaction
}

\author{
Raquel A. C. Lima ${ }^{a *}$ (1), Aluísio J. C. Pinto Júnior ${ }^{a}$,Leandro A. Pocrifka ${ }^{a}$, Raimundo R. Passos ${ }^{a}$ \\ ${ }^{a}$ Universidade Federal do Amazonas, Departamento de Química, Laboratório de Eletroquímica e \\ Energia (LEEN), 69067-005, Manaus, AM, Brasil
}

Received: August 18, 2020; Revised: March 2, 2021; Accepted: March 21, 2021

\begin{abstract}
Fuel cell is considered an energetic solution of low environmental impact which large-scale commercialization is hindered by the expensive Pt-based cathodic electrocatalyst. Therefore, its replacement by an active less-expensive metal-free electrocatalyst such as nitrogen-doped graphene (N-graphene) is desirable. To investigate nitrogen-doping influence on graphene's activity in alkaline oxygen reduction reaction (ORR), we prepared $\mathrm{N}$-graphene through thermal treatment of graphene and urea at $800{ }^{\circ} \mathrm{C}$ for $30 \mathrm{~min}$. $\mathrm{N}$-graphene exhibited higher onset potential, half-wave potential, diffusion-limited current density and kinetic current density in ORR $(0.78 \mathrm{~V}$ vs RHE, $0.63 \mathrm{~V}$ vs RHE, $-3.36 \mathrm{~mA} \mathrm{~cm}^{-2},-3.00 \mathrm{~mA} \mathrm{~cm}{ }^{-2}$, respectively) than undoped graphene ( $0.73 \mathrm{~V}$ vs RHE, $0.62 \mathrm{~V}$ vs RHE, $-2.80 \mathrm{~mA} \mathrm{~cm}^{-2},-2.23 \mathrm{~mA} \mathrm{~cm}^{-2}$, respectively), which may be attributed to nitrogen-doping, edges and defect sites in N-graphene, as revealed by elemental analysis, scanning electron microscopy and Raman spectroscopy results. This activity improvement also affected ORR's selectivity and ratedetermining step.
\end{abstract}

Keywords: Oxygen reduction reaction, metal-free electrocatalysis, nitrogen-doped graphene, thermal treatment.

\section{Introduction}

Efficient, low-cost and environmental-friendly energy solutions are imperative because of the expressive emission of greenhouse gases from fossil fuels exploitation and the projected global population growth ${ }^{1}$. Acid or alkaline polymer electrolyte membrane fuel cells (PEMFC) supplied with hydrogen are considered an attractive solution owing to the efficient generation of electricity from oxidation-reduction reactions that produce water and heat as the only byproducts.

However, their large-scale commercialization is currently hindered by the expensive platinum-based electrocatalyst used due to ORR's sluggish kinetics, which accounts for about $50 \%$ of the PEMFC production cost ${ }^{2}$. Therefore, a current growing research field in ORR electrocatalysis is that of low-cost nature-abundant metal-free electrocatalysts, especially carbon-based ones ${ }^{3}$.

Graphene is a material formed by two-dimensional sheets of $\mathrm{sp}^{2}$-hybridized carbon atoms ${ }^{4}$ and has attracted much attention from the scientific community because of its astounding thermal and electronic conductivity, large specific surface area and chemical stability ${ }^{5,6}$. However, it has very limited electrocatalytic activity in the ORR owing to the homogenous spin and charge density distribution over its atomic structure?

Nitrogen-doping has been reported as a successful approach to improve graphene's electrocatalytic activity ${ }^{3}$. The electronegativity difference between nitrogen and carbon atoms induces spin and charge density asymmetry in graphene's structure, and carbon atoms with highest positive

*e-mail: raquelalves_14@yahoo.com spin density or largest positive atomic charge are reported as active sites for the $\mathrm{ORR}^{8,9}$.

Chemical Vapor Deposition (CVD) is the most common method to synthesize $\mathrm{N}$-graphene ${ }^{10}$. However, it has the disadvantages of elaborate experimental arrangement ${ }^{11}$, possible contamination of the electrocatalyst with metal impurities ${ }^{10}$, explosion hazard due to $\mathrm{H}_{2}$ and $\mathrm{CH}_{4}$ gases used in the process ${ }^{12}$, use of toxic $\mathrm{NH}_{3}$ as nitrogen source ${ }^{10}$, time-consuming transfer process and high cost ${ }^{12}$. Thermal treatment, on the other hand, is a simple and straightforward doping method that does not require toxic precursors. It can be easily scalable and provides flexible control of experimental parameters ${ }^{13,14}$, consisting in the high temperature heating of a solid mixture of carbon and nitrogen precursors under inert atmosphere ${ }^{10}$.

In order to study only the cathodic reaction of the fuel cell, i.e. ORR, an electrochemical half-cell setup with a rotatingdisk electrode (RDE) modified with the electrocatalyst must be used. The electrocatalytic activity can then be evaluated through the reaction's onset potential $\left(\mathrm{E}_{\text {onset }}\right)$, half-wave potential $\left(\mathrm{E}_{1 / 2}\right)$, diffusion-limited current density $\left(j_{1}\right)$ and electron transfer number $(n)$. For an operational fuel cell, it is desirable for the ORR to be electrocatalysed as close as possible to the equilibrium potential, with minimum energy loss. Therefore, higher $\mathrm{E}_{\text {onset }}$ and $\mathrm{E}_{1 / 2}$ values are indicators of an effective electrocatalyst ${ }^{15,16}$. The value of $j_{1}$ depends on $n$, which indicates the reduction pathway selectivity of the electrocatalysed ORR. In alkaline medium, oxygen can be directly or indirectly completely reduced to hydroxide ion or partially reduced to the reactive hydroperoxide ion 
(Table 1) ${ }^{17}$. For fuel cell application, oxygen complete reduction is desired.

Maouche et al. (2019) used thermal treatment at $900{ }^{\circ} \mathrm{C}$ to prepare three-dimensional $\mathrm{N}$-graphene. The $\mathrm{E}_{\text {onset }}, \mathrm{E}_{1 / 2}$ and $j_{1}$ values observed for graphene $(0.665 \mathrm{~V}$ vs RHE, $0.544 \mathrm{~V}$ vs RHE and $0.88 \mathrm{~mA} \mathrm{~cm}^{-2}$, respectively) increased after nitrogen-doping $(0.879 \mathrm{~V}$ vs RHE, $0.808 \mathrm{~V}$ vs RHE and $5.21 \mathrm{~mA} \mathrm{~cm}^{-2}$, respectively) ${ }^{18}$. Kumar et al. (2016) observed a similar behavior for $\mathrm{N}$-graphene prepared by thermal treatment at $800{ }^{\circ} \mathrm{C}$. It showed higher $j_{1}$ and $n$ values for the ORR (5.08 $\mathrm{mA} \mathrm{cm}^{-2}$ and 3.2, respectively) than undoped graphene $\left(2.70 \mathrm{~mA} \mathrm{~cm}^{-2} \text { and } 2.9 \text {, respectively }\right)^{19}$.

In this report, our aim was to study how nitrogen-doping affects graphene's electrocatalytic activity in alkaline ORR. We prepared $\mathrm{N}$-graphene by thermal treatment of graphene and urea at $800^{\circ} \mathrm{C}$. Scanning electron microscopy (SEM) and Raman spectroscopy were used to study nitrogen-doping and heating effects on graphene's structure and morphology, and $\mathrm{CHN}$ elemental analysis was used to confirm the presence of nitrogen in N-graphene.

$\mathrm{N}$-graphene's electrocatalytic performance in alkaline ORR was evaluated using a RDE system. Its activity was extensively compared to those of undoped graphene and thermally-treated graphene using the aforementioned electrocatalytic parameters and also the kinetic current density $\left(j_{\mathrm{k}}\right)$ and Tafel slope $(b)$ values. Therefore, we aim to provide a careful, thorough report of the activity of $\mathrm{N}$-graphene prepared through thermal treatment in alkaline ORR, and comprehensive data that can be readily used for comparison by other works.

\section{Experimental}

\subsection{Materials preparation}

Graphene was prepared using the ball-milling technique, which is an efficient high-yielding method. In a Spex high-energy ball mill, $3 \mathrm{~g}$ of graphite flakes (99\% purity) were mixed with 3 stainless steel balls (diameter of $3 \mathrm{~cm}$ ) for $12 \mathrm{~h}$ at $1024 \mathrm{rpm}$. $\mathrm{N}$-graphene was prepared through thermal treatment of a solid mixture of graphene and urea. Graphene $(100 \mathrm{mg})$ was ultrasonicated in ultrapure water $(200 \mathrm{~mL})$ for $30 \mathrm{~min}$. After urea addition $(500 \mathrm{mg})$, the dispersion was ultrasonicated for $90 \mathrm{~min}$ and then dried at $55^{\circ} \mathrm{C}$. The obtained solid mixture was put in an alumina boat inside a tubular furnace and thermally-treated at $800{ }^{\circ} \mathrm{C}$ for $30 \mathrm{~min}\left(2{ }^{\circ} \mathrm{C} \mathrm{min}-1\right)$ under $\mathrm{N}_{2}$ flow. Pure graphene was submitted to the same heating conditions in the absence of urea to obtain thermally-treated graphene (T-graphene) as a blank sample of the process.

\subsection{Characterization}

SEM analysis was carried out on a VEGA3 scanning electron microscope (Tescan). Raman spectra of graphene,
T-graphene and N-graphene were recorded on a Confocal T64000 Raman spectrometer (Jobin Yvon) equipped with a $532 \mathrm{~nm}$ laser. Graphite's Raman spectrum reproduced here is a part of the RRUFF Project database (deposition $\mathrm{N}^{\circ}$ R050503, http://rruff.info), obtained by Marcus Origlieri on an Almega XR (Thermo) Raman spectrometer equipped with a $532 \mathrm{~nm}$ laser at $100 \%$ of $150 \mathrm{~mW}^{20}$. CHN elemental analysis was carried out on a vario MAX CHN elemental analyzer (Elementar)

\subsection{Electrochemical evaluation}

Voltammetry tests were carried out on a WaveDriver 10 potentiostat/galvanostat system (Pine Research) at room temperature using a three-electrode electrochemical cell. The reference electrode used was a reversible hydrogen electrode prepared in the aqueous electrolyte solution $(0.1 \mathrm{M}$ $\mathrm{KOH}$ ) calibrated with respect to the conventional reversible hydrogen electrode (RHE); their potential difference is $0.055 \mathrm{~V}$. A platinum foil was used as counter electrode and an electrocatalyst-modified glassy carbon $\operatorname{RDE}\left(0.1964 \mathrm{~cm}^{2}\right)$, as working electrode.

Before each measurement, the electrochemical cell, the reference electrode and the counter electrode were first washed with a solution of $10 \mathrm{wt} . \% \mathrm{KOH}$ in ethanol, and then, thoroughly washed with ultrapure water. The RDE was polished to a mirror finish using alumina polishing suspensions, and then ultrasonicated for $3 \mathrm{~min}$ in isopropyl alcohol and for another $3 \mathrm{~min}$ in ultrapure water to remove all residue of alumina. Then it was electrochemically conditioned with cyclic voltammetry $(\mathrm{CV})$ at $100 \mathrm{mV} \mathrm{s}^{-1}$ in the potential range of $0-0.6 \mathrm{~V}$ vs RHE, for typically 40 cycles or until a stable voltammogram was recorded, rinsed with ultrapure water, dried and mounted on the electrode rotator inverted shaft.

Meanwhile, $1 \mathrm{mg}$ of the electrocatalyst was ultrasonicated in $1 \mathrm{~mL}$ of ultrapure water, isopropyl alcohol and $5 \mathrm{wt} . \%$ Nafion solution (volume ratio of 79.5:20:0.5, respectively). Then, $30 \mu \mathrm{L}$ of the electrocatalyst ink was transferred using a micropipette and spread over the surface of RDE's glassy carbon disk, yielding a electrocatalyst loading of $152.75 \mu \mathrm{g}$ $\mathrm{cm}^{-2}$, and the RDE was rotated at $500 \mathrm{rpm}$ until complete drying of the electrocatalytic film. The rotational drying method was reported elsewhere and yields reproducible, visually homogenous electrocatalytic films ${ }^{21}$.

A potential range of $0-1 \mathrm{~V}$ vs RHE was used for both CV and linear sweep voltammetry (LSV) subsequent measurements. Before them, the electrolyte solution was purged with $\mathrm{N}_{2}$ or saturated with $\mathrm{O}_{2}$ for at least 20 min, and during them, the $\mathrm{N}_{2}$ or $\mathrm{O}_{2}$ flux was maintained in the solution, away from the RDE's surface. CV measurements were recorded in $\mathrm{N}_{2}$ purged solution in the anodic direction with a scan rate of $50 \mathrm{mV} \mathrm{s}^{-1}$. LSV measurements were recorded in the cathodic direction with a scan rate of $10 \mathrm{mV} \mathrm{s}^{-1}$ in

Table 1. Oxygen reduction pathways in alkaline medium.

\begin{tabular}{|c|c|c|}
\hline Reduction pathway & Chemical equation & Standard reduction potential \\
\hline Direct complete reduction & $\mathrm{O}_{2(\mathrm{~g})}+2 \mathrm{H}_{2} \mathrm{O}_{(\mathrm{l})}+4 \mathrm{e}^{-} \rightarrow 4 \mathrm{OH}_{(\mathrm{aq})}^{-}$ & $0.401 \mathrm{~V}$ vs RHE \\
\hline Indirect complete reduction & $\begin{array}{c}\mathrm{O}_{2(\mathrm{~g})}+\mathrm{H}_{2} \mathrm{O}_{(\mathrm{l})}+2 \mathrm{e}^{-} \rightarrow \mathrm{HO}_{2}^{-}(\mathrm{aq}) \\
\mathrm{HO}_{2(\mathrm{aq})}^{-}+\mathrm{OH}^{-} \\
\mathrm{H}_{2} \mathrm{O}_{(\mathrm{l})}+2 \mathrm{e}^{-} \rightarrow 3 \mathrm{OH}_{(\mathrm{aq})}^{-}\end{array}$ & $-0.065 \mathrm{~V}$ vs RHE \\
\hline Partial reduction & $\mathrm{O}_{2(\mathrm{~g})}+\mathrm{H}_{2} \mathrm{O}_{(\mathrm{l})}+2 \mathrm{e}^{-} \rightarrow \mathrm{HO}_{2(\text { (aq) }}^{-}+\mathrm{OH}_{(\mathrm{aq})}^{-}$ & $0.867 \mathrm{~V}$ vs RHE \\
\hline
\end{tabular}



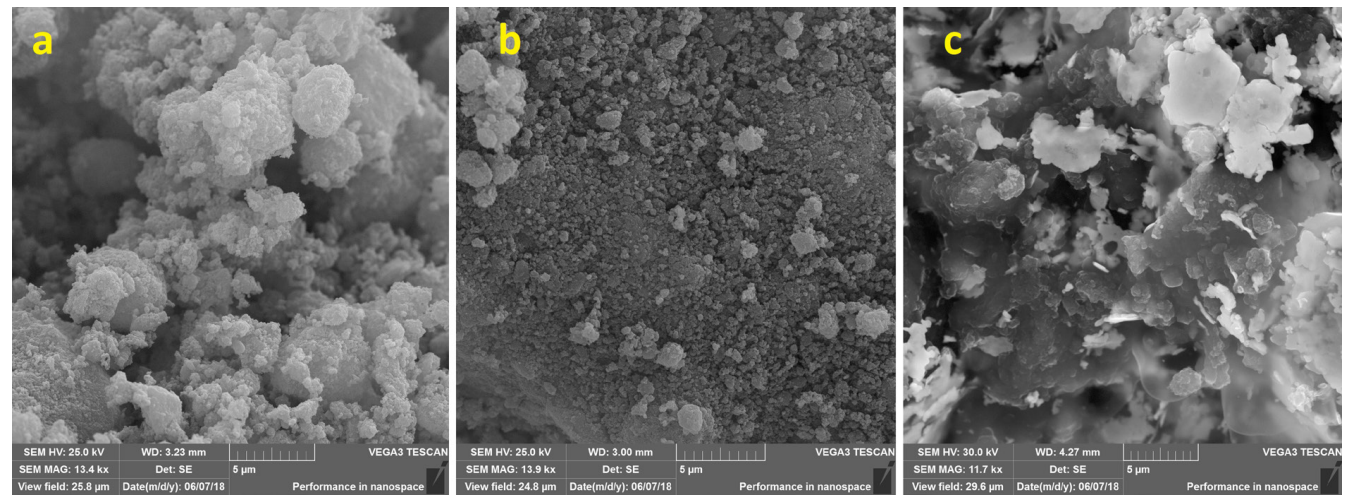

Figure 1. SEM images at $5 \mu \mathrm{m}$ scale of (a) graphene, (b) T-graphene and (c) N-graphene.

$\mathrm{O}_{2}$ and in $\mathrm{N}_{2}$ saturated electrolyte solution, with different electrode rotation rates $(400,900,1600$ and $2500 \mathrm{rpm})$. The obtained curves in each of these rates were subtracted in order to correct the background current in the ORR curves.

ORR curves were also iR-drop corrected. The electrolyte resistance value ( $35.6 \Omega$ on average) was obtained from the high-frequency region of the electrochemical impedance spectra of the electrocatalysts in 0.1 M KOH. An Autolab PGSTAT302N potentiostat/galvanostat system (Metrohm) was used to record these spectra in OCP condition with a potential perturbation of $25 \mathrm{mV}$ within the frequency range of $10 \mathrm{mHz}$ to $100 \mathrm{kHz}$. Current values were normalized with respect to the RDE geometric surface area $\left(0.1964 \mathrm{~cm}^{2}\right)$.

\section{Results and Discussion}

The morphology observed for graphene consisted of sphere-like particles with different sizes (Figure 1a), which are most likely resultant from the sliding and curving of graphite layers upon the impact of the stainless steel balls ${ }^{22}$, and has also been reported by other works for samples obtained through the ball-milling of graphite ${ }^{22,23}$. As revealed by SEM images, thermal treatment and nitrogen-doping modified graphene's morphology in different ways.

Thermal treatment caused a significant particle size reduction, as observed for T-graphene (Figure 1b). On the other hand, particles with microplatelet structure and defective edges could be observed for $\mathrm{N}$-graphene (Figure 1c). The effectiveness of thermal treatment as a doping process was confirmed by elemental analysis data, which revealed a nitrogen bulk composition of $0.714 \%$ in N-graphene.

The main features of graphene's Raman spectrum (D, $\mathrm{G}$ and $2 \mathrm{D}$ bands) appeared in the Raman spectra of all the prepared electrocataysts (Figure 2). G band is a first order Raman scattering process originated from the $E_{2 g}$ in-plane vibration of $\mathrm{sp}^{2}$ graphitic carbon atoms ${ }^{16,24,25}$. $\mathrm{D}$ band is assigned to the $\mathrm{A}_{1 \mathrm{~g}}$ in-plane breathing vibrational modes of $\mathrm{sp}^{2}$ rings and is originated from a second-order scattering process in graphene involving one iTO phonon and one defect ${ }^{16,24,26}$. Because it is defect-activated, D band indicates the presence of symmetry-breaking perturbations such as edges, non-sixatoms rings, functionalities, doped heteroatoms, $\mathrm{sp}^{3}$ defects, vacancy sites and grain boundaries ${ }^{27-29} .2 \mathrm{D}$ band, which is characteristic of graphene structures ${ }^{26,30,31}$, is a second-order

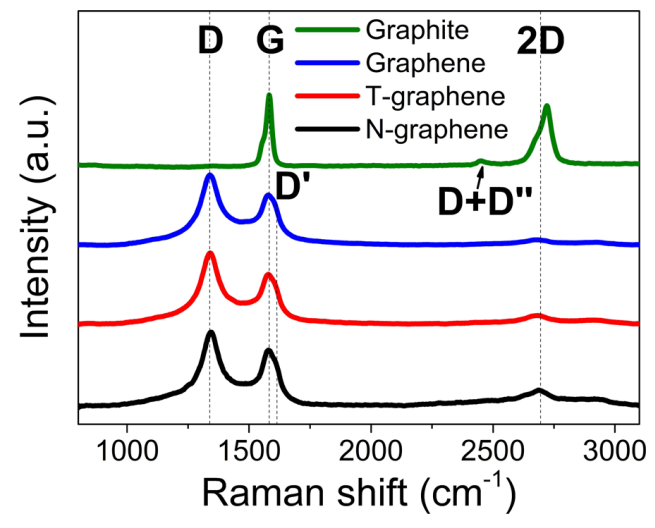

Figure 2. Raman spectra of the electrocatalysts and of graphite.

Table 2. Raman bands positions and $I_{\mathrm{D}} / I_{\mathrm{G}}$ ratios for the electrocatalysts.

\begin{tabular}{ccccc}
\hline \multirow{2}{*}{ Electrocatalyst } & \multicolumn{3}{c}{ Band position $\left(\mathrm{cm}^{-1}\right)$} & \multirow{2}{*}{$I_{\mathrm{D}} / I_{\mathrm{G}}$} \\
\cline { 2 - 4 } & $\mathrm{D}$ & $\mathrm{G}$ & $2 \mathrm{D}$ & \\
\hline Graphene & 1341.52 & 1579.80 & 2706.60 & 1.70 \\
\hline T-graphene & 1340.78 & 1580.57 & 2694.13 & 1.82 \\
\hline N-graphene & 1343.34 & 1582.51 & 2692.61 & 1.84 \\
\hline
\end{tabular}

Raman scattering process as well, but involves two iTO phonons near the K point and is not defect-activated ${ }^{24,32,33}$.

For graphite, the almost imperceptible D band indicates low density of defect in the material, and its feeble D+D" band at approximately $2452 \mathrm{~cm}^{-1}$ results from a combination of a D phonon and an acoustic longitudinal phonon, D" 34 . The 2D band for graphite is asymmetric, whether for graphene it is symmetric, and consists of two components, because the increase in graphene layer number causes a split of the electronic band structure ${ }^{34}$. The D' band that appears as a shoulder of the $\mathrm{G}$ band for graphene, T-graphene and $\mathrm{N}$-graphene indicates the presence of few-layered graphene ${ }^{22,35}$.

These different features between the Raman spectra of graphene and graphite (Figure 2), e.g. the increased intensity of the $\mathrm{D}$ band, the more symmetric shape of the $2 \mathrm{D}$ band, the broadening of the $\mathrm{G}$ band and the appearance of the D' band, indicate that graphene flakes were successfully obtained by the ball-milling of graphite in this work. This same evolution of Raman spectral features was also reported in other works for the mechanochemical exfoliation of graphite to obtain graphene ${ }^{22,35}$. 
The $\mathrm{G}$ and $\mathrm{D}$ bands of $\mathrm{N}$-graphene were shifted to higher frequencies compared to the bands of graphene (Table 2). Since chemical doping changes the electronic state of graphene and breaks the symmetry of its $\mathrm{sp}^{2}$ carbon network ${ }^{33}$, D and $\mathrm{G}$ bands upshift is expected for doped-graphene regardless of the type of doping ${ }^{13,33}$. Therefore, the observed Raman spectrum of $\mathrm{N}$-graphene corroborates the elemental analysis to confirm the effectiveness of the thermal treatment to prepare this electrocatalyst.

The ratio of $\mathrm{D}$ and $\mathrm{G}$ bands intensity $\left(I_{\mathrm{D}} / I_{\mathrm{G}}\right)$ is commonly used to evaluate the degree of structural disorder in graphene materials ${ }^{13,25}$. Thermal treatment and nitrogen-doping introduced defects in the structure of graphene and decreased its graphitization degree, as indicated by the higher $I_{\mathrm{D}} / I_{\mathrm{G}}$ values of T-graphene and $\mathrm{N}$-graphene compared to that of graphene (Table 2). This is most likely due to edges exposure when oxygen moieties are removed during heating ${ }^{13,28}$ and defects originated from the substitutional doping of nitrogen atoms in the framework of graphene $e^{13,14,25}$.

The cyclic voltammetry profile of the electrocatalysts was typical of graphene-based materials - featureless semirectangular waves (Figure 3). Regarding ORR electrocatalysis, none of the electrocatalysts investigated in this work exhibited comparable activity to Pt/C 20 wt.\% (Figure 4). Despite that, nitrogen-doping enhanced graphene's activity (Figure 4), as evidenced by the higher $\mathrm{E}_{\text {onset }}, \mathrm{E}_{1 / 2}$ and $j_{1}$ values registered for $\mathrm{N}$-graphene, compared to the undoped electrocatalysts (Figure 4 and Table 3).

An ORR diffusion-limited current density plateau, commonly observed for platinum-based electrocatalysts ${ }^{36}$, was not obtained for our electrocatalysts (Figure 4). This behavior has also been reported for other metal-free electrocatalysts ${ }^{30,32}$. Therefore, $j_{1}$ values were sampled in the middle of the diffusion control potential range $(0.05-0.55 \mathrm{~V}$ vs RHE), at $0.3 \mathrm{~V}$ vs RHE (Table 3). Graphene and T-graphene ORR activities were very similar (Figure 4 and Table 3 ), indicating that, in the case of graphene prepared through the ball-milling method, thermal treatment does not enhance its activity in the ORR.

ORR curves were recorded at different electrode rotation rates for graphene (Figure 5), T-graphene (Figure 6) and $\mathrm{N}$-graphene (Figure 7) in order to calculate $n$ values from their Koutecký-Levich plots (Figure 8). For each electrocatalyst, current density values were sampled in each rotation rate at $0.63 \mathrm{~V}$ vs $\mathrm{RHE}$ and at $0.3 \mathrm{~V}$ vs RHE, these potential values are in the mixed kinetic-diffusion control $(0.55-0.70 \mathrm{~V}$ vs RHE) and in the diffusion control potential ranges $(0.05-0.55 \mathrm{~V}$ vs RHE), respectively.

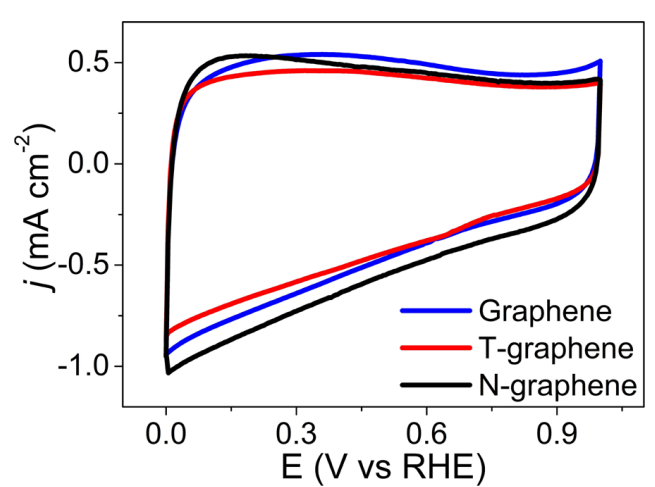

Figure 3. Cyclic voltammograms of the electrocatalysts in $\mathrm{N}_{2}$ saturated $0.1 \mathrm{M} \mathrm{KOH}$ at $50 \mathrm{mV} \mathrm{s}^{-1}$.

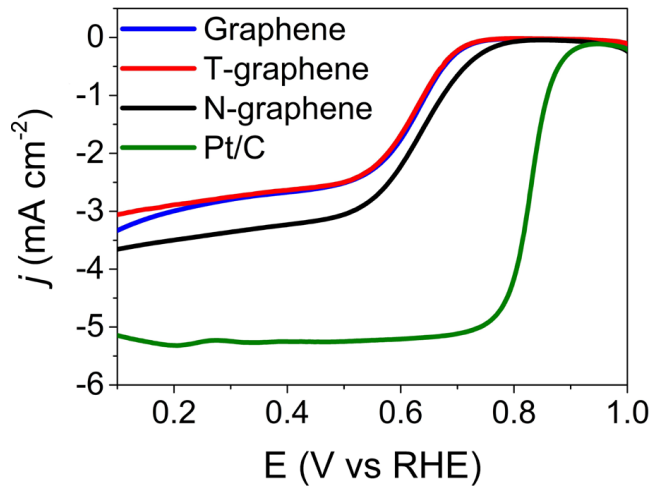

Figure 4. ORR curves of the electrocatalysts and of $\mathrm{Pt} / \mathrm{C} 20 \mathrm{wt} . \%$ (Pt loading of $25.46 \mu \mathrm{g}_{\mathrm{Pt}} \mathrm{cm}^{-2}$ ) in $\mathrm{O}_{2}$ saturated $0.1 \mathrm{M} \mathrm{KOH}$ at 10 $\mathrm{mV} \mathrm{s}^{-1}$ and $1600 \mathrm{rpm}$.

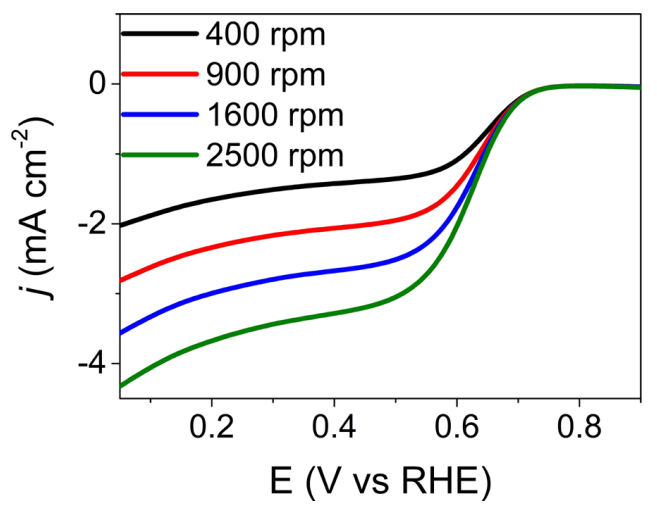

Figure 5. ORR curves in $\mathrm{O}_{2}$ saturated $0.1 \mathrm{M} \mathrm{KOH}$ at $10 \mathrm{mV} \mathrm{s}^{-1}$ and different electrode rotation rates for graphene.

Table 3. ORR activity parameters extracted from Figures 4, 8 and 9 for the electrocatalysts.

\begin{tabular}{ccccc}
\hline & Graphene & T-graphene & N-graphene \\
\hline & $\mathrm{E}_{\text {onset }}(\mathrm{V}$ vs RHE $)$ & 0.73 & 0.72 & 0.78 \\
\hline $\mathrm{E}_{1 / 2}(\mathrm{~V}$ vs RHE $)$ & 0.62 & 0.62 & 0.63 \\
\hline$j_{1}\left(\mathrm{~mA} \mathrm{~cm}^{-2}\right)$ & -2.80 & -2.75 & -3.36 \\
\hline \multirow{2}{*}{$n$} & $j_{\mathrm{k}}\left(\mathrm{mA} \mathrm{cm}^{-2}\right)$ & -2.23 & -2.17 & -3.00 \\
\hline & at $0.63 \mathrm{~V} \mathrm{vs} \mathrm{RHE}$ & 2.1 & 1.9 & 2.9 \\
\cline { 2 - 5 } & at $0.3 \mathrm{~V} \mathrm{vs} \mathrm{RHE}^{-1}$ & 2.3 & 2.2 & 2.9 \\
\hline
\end{tabular}


The slope of the line for each potential value in the Koutecký-Levich plots of the electrocatalysts was used to estimate the $n$ value through the Koutecký-Levich equation (Equation 1), where $j$ is the measured current density, $j_{1}$ is the diffusion-limited current density, $j_{k}$ is the kinetic current density and $\omega$ is the electrode rotation rate. $B$ factor is defined by Equation 2, where $F$ is the Faraday constant $\left(96,485 \mathrm{C} \mathrm{mol}^{-1}\right), D_{\mathrm{O}}$ is the diffusion coefficient of oxygen in the electrolyte $\left(1.910^{-5} \mathrm{~cm}^{2} \mathrm{~s}^{-1}\right), v$ is the kinematic viscosity of the electrolyte $\left(0.01 \mathrm{~cm}^{2} \mathrm{~s}^{-1}\right), C_{\mathrm{O}}$ is the

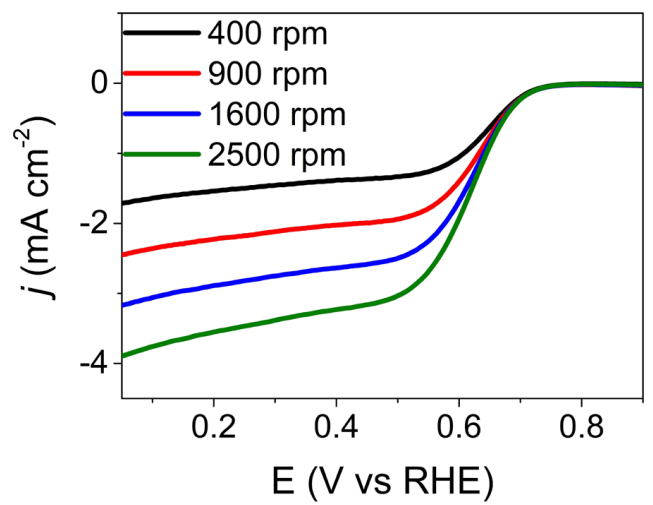

Figure 6. ORR curves in $\mathrm{O}_{2}$ saturated $0.1 \mathrm{M} \mathrm{KOH}$ at $10 \mathrm{mV} \mathrm{s}^{-1}$ and different electrode rotation rates for T-graphene.

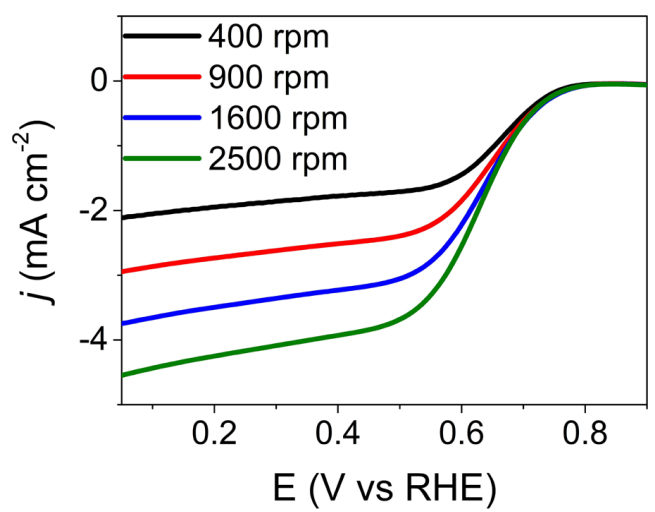

Figure 7. ORR curves in $\mathrm{O}_{2}$ saturated $0.1 \mathrm{M} \mathrm{KOH}$ at $10 \mathrm{mV} \mathrm{s}^{-1}$ and different electrode rotation rates for $\mathrm{N}$-graphene.

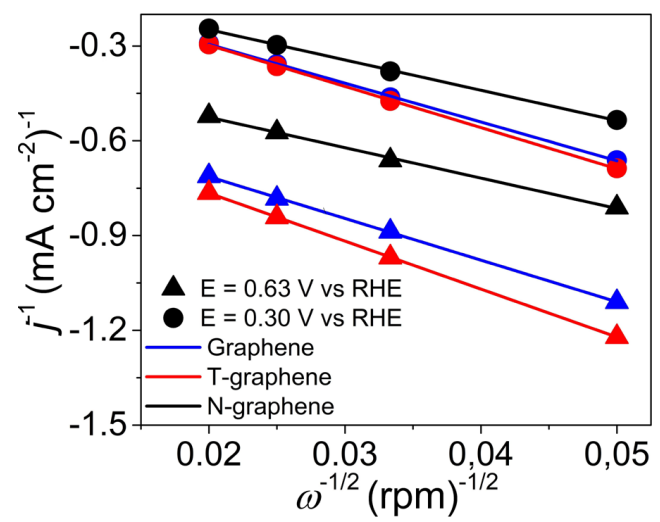

Figure 8. Koutecký-Levich plots of the electrocatalysts. solubility of oxygen in the electrolyte $\left(1.210^{-6} \mathrm{~mol} \mathrm{~cm}^{-3}\right)$ and 0.2 is a constant used when the electrode rotation rate is expressed in $\mathrm{rpm}^{13}$.

$\frac{1}{\mathrm{j}}=\frac{1}{\mathrm{j}_{1}}+\frac{1}{\mathrm{j}_{\mathrm{k}}}=\frac{1}{\mathrm{~B} \omega^{1 / 2}}+\frac{1}{\mathrm{j}_{\mathrm{k}}}$

$\mathrm{B}=0.2 \mathrm{nFD}_{\mathrm{O}}^{2 / 3} \mathrm{v}^{-1 / 6} \mathrm{C}_{\mathrm{O}}$

Nitrogen-doping increased graphene's $n$ value for the ORR (Table 3). Graphene and T-graphene lead ORR through the 2 electron reduction pathway, i.e. the reduction of $\mathrm{O}_{2}$ molecule to $\mathrm{HOO}^{-}$, in the entire monitored potential range (Table 3 ). After nitrogen-doping, $n$ value increased to 3 (Table 3 ), indicating that $\mathrm{N}$-graphene promotes oxygen partial and complete reduction pathways simultaneously, with possible formation of $\mathrm{HOO}^{-}$and $\mathrm{OH}^{-}$species. This combined 2 and 4 electrons reduction process has also been reported in other works for nitrogen-doped carbon-based electrocatalysts ${ }^{28,37-39}$

Our result is similar to that reported by Kim et al. (2020) for a nitrogen-doped reduced graphene oxide electrocatalyst at $1.0 \mathrm{~mA} \mathrm{~cm}^{-2}$, that was prepared by the thermal treatment of a solid mixture of urea and graphene oxide (5:1 mass ratio) at $800{ }^{\circ} \mathrm{C}$ for 30 min under $\mathrm{N}_{2}$ atmosphere (almost the same conditions used in our work, except for the carbon precursor and preparation procedure of the solid mixture prior to thermal treatment) ${ }^{40}$. Kim et al. (2020) found out that the partial and complete reduction pathways in their electrocatalyst were completely independent from each other and suggested that more than one type of site or structure in the electrocatalyst were active in the ORR.

Nitrogen-doping also increased graphene's $j_{k}$ value in the ORR (Table 3), another parameter used to evaluate the electrocatalytic activity ${ }^{15}$. Values of $j_{\mathrm{k}}$ were extracted through the intercept of each electrocatalyst's Koutecký-Levich plot at $0.63 \mathrm{~V}$ vs RHE, which according to the Koutecký-Levich equation, corresponds to an infinite value of $\omega$ where current density is no longer affected by mass transport limitations ${ }^{41}$. For this reason, Shin et al. (2015) consider $j_{\mathrm{k}}$ a better parameter to judge ORR activity than $j_{1}$, which is dependent on the oxygen concentration in the electrolyte and, therefore, can be affected by different pressure and temperature conditions ${ }^{42}$.

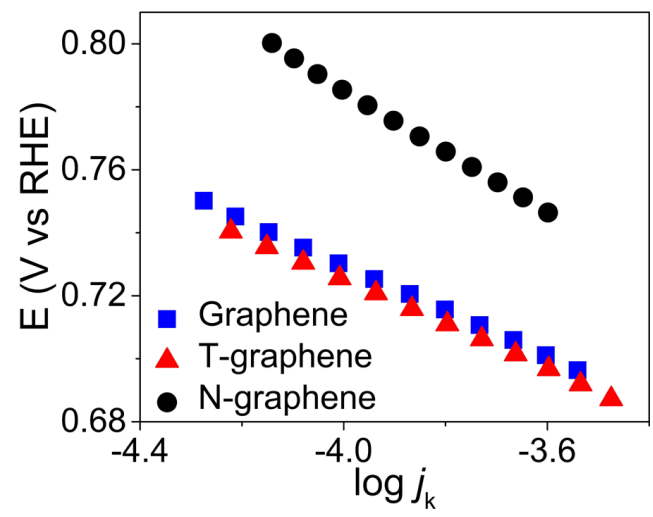

Figure 9. Tafel plots of the electrocatalysts at $1600 \mathrm{rpm}$. 
Tafel plots were used to gain further understanding regarding the electrocatalysts activity in the ORR (Figure 9). Tafel relation is the linear relation between $\log j$ and potential, since the dependence of $j$ on potential is exponential ${ }^{43}$. This relation can only be observed for irreversible reactions of sluggish kinetics that require significant activation overpotentials ${ }^{44}$, such as ORR. The values of $b$ extracted from these plots in the kinetic control potential range $(0.68-0.80 \mathrm{~V}$ vs RHE, for our electrocatalysts), where there is no mass-transport limitation for $j^{45}$, can be used to indicate the ORR ratedetermining step (rds) for each electrocatalyst ${ }^{46,47}$.

For ORR, two $b$ values are commonly observed: $60 \mathrm{mV} \mathrm{dec}{ }^{-1}$ or $120 \mathrm{mV} \mathrm{dec}^{-1}$, indicating that the rds is either a chemical or an electrochemical step, respectively ${ }^{46}$. Considering the associative mechanism of the electrocatalyzed ORR, this chemical step would be the reaction of adsorbed $\mathrm{O}_{2}{ }^{-}$species with $\mathrm{H}_{2} \mathrm{O}$ to form $\mathrm{OH}^{-}$and adsorbed $\mathrm{OOH}$, and the electrochemical step would be the first electron transfer step to adsorbed $\mathrm{O}_{2}$ to form $\mathrm{O}_{2}^{-}$species, if the Tafel slope was obtained at low overpotentials ${ }^{47}$. These values may vary depending on the electrode material and the potential range ${ }^{48}$. In this work, $b$ values obtained for graphene and T-graphene (Table 3) indicated that a chemical step is most likely the rds. N-graphene's $b$ value (Table 3 ), on the contrary, indicated that an electrochemical step is most likely the rds. Therefore, nitrogen-doping affected the ORR mechanism.

Similar $b$ values to the ones we found have been reported for other electrocatalysts. For example, Chai et al. (2019) reported a $b$ value of $75.4 \mathrm{mV} \mathrm{dec}^{-1}$ for a solid carbon spheres electrocatalyst ${ }^{49}$. Ramirez-Barria et al. (2019) prepared a nitrogen-doped reduced graphene oxide electrocatalyst through the thermal annealing of reduced graphene oxide in ammonia-containing atmosphere at $700{ }^{\circ} \mathrm{C}$, which was synthesized from a modified Brodie's method using 100 mesh graphite powder ${ }^{39}$. This electrocatalyst's $b$ value was $99 \mathrm{mV} \mathrm{dec}{ }^{-1}$. Miao et al. (2017) prepared nitrogendoped reduced graphene oxide electrocatalysts through a hydrothermal method and posterior thermal treatment at 600 and at $700{ }^{\circ} \mathrm{C}$, which exhibited $b$ values of 95.3 and $94.3 \mathrm{mV} \mathrm{dec}^{-1}$, respectively ${ }^{38}$. All these experiments were conducted in $\mathrm{O}_{2}$ saturated $0.1 \mathrm{M} \mathrm{KOH}$ electrolyte solution.

The elemental analysis indicated the presence of nitrogen in $\mathrm{N}$-graphene electrocatalyst after thermal treatment of graphene with urea at $800^{\circ} \mathrm{C}$. The enhanced activity of $\mathrm{N}$-graphene in the ORR, compared to the undoped electrocatalysts, might be ascribed to the incorporation of nitrogen atoms in the framework of graphene. As explained by Zhang and Xia (2011), this incorporation changes the atomic charge and spin density distribution of $\mathrm{N}$-graphene, and leads to the formation of active sites, carbon atoms with highest spin density or largest positive atomic charge ${ }^{8}$.

$\mathrm{N}$-graphene SEM image revealed a morphology enriched with exposed edges, which are reported as highly active ORR sites $^{50-52}$. The edges exposure and the exfoliated structure may facilitate the accessibility of $\mathrm{O}_{2}$ molecules to the active sites. The $I_{\mathrm{D}} / I_{\mathrm{G}}$ ratio obtained from the Raman spectrum of $\mathrm{N}$-graphene indicated a highly defective structure. This defective structure might be associated with N-graphene's higher activity in the ORR, compared to graphene and T-graphene because, as explained by Ortiz-Medina et al.
(2019), structural defects modify atomic orbitals and create localized electronic states that enhance electrocatalytic activity $^{53}$.

In our work, most likely a synergistic effect of nitrogen incorporation and edge and defect sites may have contributed to N-graphene's activity in the ORR, as observed by its higher $\mathrm{E}_{\text {onset }}, \mathrm{E}_{1 / 2}, j_{1}$ and $j_{\mathrm{k}}$ values compared to undoped graphene and the blank sample, T-graphene. This improved activity also altered the oxygen reduction pathway selectivity and the rds of the ORR electrocatalysed by N-graphene.

\section{Conclusions}

Nitrogen-doping improved graphene's activity in alkaline ORR and altered its oxygen reduction pathway selectivity and rds. This improvement did not originate from heat treatment only, since T-graphene's activity in ORR was similar to that of graphene, but it is likely that a combined influence of nitrogen-doping, edges and defect sites simultaneously contributed to the reported activity of N-graphene. Future investigations should focus on the optimization of thermal treatment conditions in order to achieve a $\mathrm{N}$-graphene electrocatalyst with higher activity in the ORR.

\section{Acknowledgments}

The authors thank CNPq (Grant \# 456336/2013-3), FAPEAM (Grant \# 062.00801/2015), LTMOE-INPA for SEM images, LTSP-INPA for elemental analysis, and UNICAMP Institute of Chemistry for Raman spectroscopy analysis. This study was financed in part by the Coordenação de Aperfeiçoamento de Pessoal de Nível Superior (CAPES), Brazil, finance code 001 .

\section{References}

1. United Nations. World Population Prospects: The 2017 revision, key findings and advance tables. New York: United Nations; 2017.

2. Martinez U, Komini Babu S, Holby EF, Chung HT, Yin X, Zelenay P. Progress in the development of Fe-Based PGM-free electrocatalysts for the oxygen reduction reaction. Adv Mater. 2019;31:1806545.

3. Wu Z, Song M, Wang J, Liu X. Recent progress in nitrogendoped metal-free electrocatalysts for oxygen reduction reaction. Catalysts. 2018;8:196.

4. Novoselov KS, Geim AK, Morozov SV, Jiang D, Zhang Y, Dubonos SV, et al. Electric field effect in atomically thin carbon films. Science. 2004;306:666-9.

5. Wang X, Shi G. An introduction to the chemistry of graphene. Phys Chem Chem Phys. 2015;17(43):28484-504.

6. Wu G, Santandreu A, Kellogg W, Gupta S, Ogoke O, Zhang $\mathrm{H}$, et al. Carbon nanocomposite catalysts for oxygen reduction and evolution reactions: from nitrogen doping to transition-metal addition. Nano Energy. 2016;29:83-110.

7. Gao K, Wang B, Tao L, Cunning BV, Zhang Z, Wang S, et al. Efficient metal-free electrocatalysts from N-Doped carbon nanomaterials: mono-doping and co-doping. Adv Mater. 2019;31:1805121.

8. Zhang L, Xia Z. Mechanisms of oxygen reduction reaction on nitrogen-doped graphene for fuel cells. J Phys Chem C. 2011;115:11170-6.

9. Geng D, Ding N, Andy Hor TS, Liu Z, Sun X, Zong Y. Potential of metal-free "graphene alloy" as electrocatalysts for oxygen 
reduction reaction. J Mater Chem A Mater Energy Sustain. 2015;3:1795-810.

10. Zhuang S, Nunna BB, Mandal D, Lee ES. A review of nitrogendoped graphene catalysts for proton exchange membrane fuel cells-synthesis, characterization, and improvement. NanoStructures and Nano-Objects. 2018;15:140-52.

11. Sai Pavan AS, Ramanan SR. A study on corrosion resistant graphene films on low alloy steel. Appl Nanosci. 2016;6(8):117581.

12. Su H, Hu YH. Recent advances in graphene-based materials for fuel cell applications. Energy Sci Eng. 2020;0(August):1-26.

13. Lin Z, Waller G, Liu Y, Liu M, Wong C-P. Facile synthesis of Nitrogen-Doped graphene via pyrolysis of graphene oxide and urea, and its electrocatalytic activity toward the oxygenreduction reaction. Adv Energy Mater. 2012;2(7):884-8.

14. Soo LT, Loh KS, Mohamad AB, Daud WRW, Wong WY. Effect of nitrogen precursors on the electrochemical performance of nitrogen-doped reduced graphene oxide towards oxygen reduction reaction. J Alloys Compd. 2016;677:112-20.

15. Jiao Y, Zheng Y, Jaroniec M, Qiao SZ. Origin of the electrocatalytic oxygen reduction activity of graphene-based catalysts: a roadmap to achieve the best performance. J Am Chem Soc. 2014;136(11):4394-403.

16. Daems N, Sheng X, Vankelecom IFJ, Pescarmona PP. Metalfree doped carbon materials as electrocatalysts for the oxygen reduction reaction. J Mater Chem A Mater Energy Sustain. 2014;2(12):4085-110.

17. Zhang J. PEM fuel cells electrocatalysts and catalysts layers - Fundamentals and applications. Vancouver: Springer; 2008.

18. Maouche C, Zhou Y, Li B, Cheng C, Wu Y, Li J, et al. Thermal treated three-dimensional $\mathrm{N}$-doped graphene as efficient metal free-catalyst for oxygen reduction reaction. J Electroanal Chem (Lausanne Switz). 2019;853(October):113536.

19. Kumar MP, Raju MM, Arunchander A, Selvaraj S, Kalita G, Narayanan TN, et al. Nitrogen doped graphene as metal free electrocatalyst for efficient oxygen reduction reaction in alkaline media and its application in anion exchange membrane fuel cells. J Electrochem Soc. 2016;163(8):F848-55.

20. Lafuente B, Downs RT, Yang H, Stone N. Highlights in. In: Armbruster T, Danisi RM, editors. Highlights in mineralogical crystallography. Berlim: W. De Gruyter; 2015. p. 1-30.

21. Garsany Y, Singer IL, Swider-Lyons KE. Impact of film drying procedures on $\mathrm{RDE}$ characterization of $\mathrm{Pt} / \mathrm{VC}$ electrocatalysts. J Electroanal Chem (Lausanne Switz). 2011;662(2):396-406.

22. Mahmoud AED, Stolle A, Stelter M. Sustainable synthesis of high-surface-area graphite oxide via dry ball milling. ACS Sustain Chem\& Eng. 2018;6(5):6358-69.

23. Xing T, Sunarso J, Yang W, Yin Y, Glushenkov AM, Li LH, et al. Ball milling: A green mechanochemical approach for synthesis of nitrogen doped carbon nanoparticles. Nanoscale. 2013;5(17):7970-6.

24. Malard LM, Pimenta MA, Dresselhaus G, Dresselhaus MS. Raman spectroscopy in graphene. Phys Rep. 2009;473(5-6):5187.

25. Geng D, Yang S, Zhang Y, Yang J, Liu J, Li R, et al. Nitrogen doping effects on the structure of graphene. Appl Surf Sci. 2011;257(21):9193-8.

26. Xing Z, Ju Z, Zhao Y, Wan J, Zhu Y, Qiang Y, et al. One-pot hydrothermal synthesis of Nitrogen-doped graphene as highperformance anode materials for lithium ion batteries. Sci Rep. 2016;6:26146.

27. Nanda SS, Kim MJ, Yeom KS, An SSA, Ju H, Yi DK. Raman spectrum of graphene with its versatile future perspectives. TrAC -. Trends Analyt Chem. 2016;80:125-31.

28. Li D, Duan X, Sun H, Kang J, Zhang H, Tade MO, et al. Facile synthesis of nitrogen-doped graphene via low-temperature pyrolysis: the effects of precursors and annealing ambience on metal-free catalytic oxidation. Carbon. 2017;115:649-58.
29. Beams R, Cançado L, Novotny L. Raman characterization of defects and dopants in graphene. J Phys Condens Matter. 2015;27:083002.

30. Lu ZJ, Xu MW, Bao SJ, Tan K, Chai H, Cai CJ, et al. Facile preparation of nitrogen-doped reduced graphene oxide as a metal-free catalyst for oxygen reduction reaction. J Mater Sci. 2013;48(23):8101-7.

31. Zhang J, Sun Y, Zhu J, Kou Z, Hu P, Liu L, et al. Defect and pyridinic nitrogen engineering of carbon-based metalfree nanomaterial toward oxygen reduction. Nano Energy. 2018;52(May):307-14.

32. Liu Y, Li J, Li W, Li Y, Zhan F, Tang H, et al. Exploring the nitrogen species of nitrogen doped graphene as electrocatalysts for oxygen reduction reaction in Al-air batteries. Int J Hydrogen Energy. 2016;41(24):10354-65.

33. Solati N, Mobassem S, Kahraman A, Ogasawara H, Kaya S. A comprehensive study on the characteristic spectroscopic features of nitrogen doped graphene. Appl Surf Sci. 2019;495(June):143518.

34. Roscher S, Hoffmann R, Ambacher O. Determination of the graphene-graphite ratio of graphene powder by Raman 2D band symmetry analysis. Anal Methods. 2019;11:1224-8.

35. Wang Q, Liu X, Xi H, Yuan R, Zhang C. First direct exfoliation and nitrogen-doping of graphite to graphene via solid-state pan milling for high- performance lithium ion battery. Nano Adv. 2018;3(2):27-34.

36. Garsany Y, Ge J, St-Pierre J, Rocheleau R, Swider-Lyons KE. Analytical procedure for accurate comparison of rotating disk electrode results for the oxygen reduction activity of $\mathrm{Pt} / \mathrm{C}$. J Electrochem Soc. 2014;161(5):F628-40.

37. Lai L, Potts JR, Zhan D, Wang L, Poh CK, Tang C, et al. Exploration of the active center structure of nitrogen-doped graphene-based catalysts for oxygen reduction reaction. Energy Environ Sci. 2012;5(7):7936-42.

38. Miao H, Li S, Wang Z, Sun S, Kuang M, Liu Z, et al. Enhancing the pyridinic $\mathrm{N}$ content of Nitrogen-doped graphene and improving its catalytic activity for oxygen reduction reaction. Int J Hydrogen Energy. 2017;42:28298-308.

39. Ramirez-Barria CS, Fernandes DM, Freire C, Villaro-Abalos E, Guerrero-Ruiz A, Rodríguez-Ramos I. Upgrading the properties of reduced graphene oxide and nitrogen-doped reduced graphene oxide produced by thermal reduction toward efficient ORR electrocatalysts. Nanomaterials (Basel). 2019;9:1761.

40. Kim HW, Bukas VJ, Park H, Park S, Diederichsen KM, Lim J, et al. Mechanisms of two-electron and four-electron electrochemical oxygen reduction reactions at nitrogen-doped reduced graphene oxide. ACS Catal. 2020;10(1):852-63.

41. Dalton F. ECS Class: Historical origins of the rotating ring-disk electrode. Electrochem Soc Interface. 2016;25(3):50-9.

42. Shin D, Jeong B, Choun M, Ocon JD, Lee J. Diagnosis of the measurement inconsistencies of carbon-based electrocatalysts for the oxygen reduction reaction in alkaline media. RSC Advances. 2015;5(2):1571-80.

43. Brett CMA, Brett AMO. Electrochemistry: principles, methods and strategies. 1st ed. New York: Oxford University Press; 1993.

44. Bard AJ, Faulkner LR, Swain E, Robey C. Electrochemical methods: Fundamentals and applications. 2nd ed. New York: John Wiley \& Sons; 2001.

45. Gileadi E. Electrode kinetics for chemists, chemical engineers, and materials scientists. 1st ed. New York: VCH Publishers; 1993.

46. Fletcher S. Tafel slopes from first principles. J Solid State Electrochem. 2009;13(4):537-49.

47. Shinagawa T, Garcia-Esparza AT, Takanabe K. Insight on Tafel slopes from a microkinetic analysis of aqueous electrocatalysis for energy conversion. Sci Rep. 2015;5:13801.

48. Song C, Zhang J. Electrocatalytic oxygen reduction reaction. In: Zhang J, editor. PEM fuel cell electrocatalysts and catalyst 
layers: fundamentals and applications. 1st ed. London: Springer; 2008. p. 89-134.

49. Chai L, Zhang L, Wang X, Xu L, Han C, Li TT, et al. Bottom-up synthesis of MOF-derived hollow N-doped carbon materials for enhanced ORR performance. Carbon. 2019;146:248-56.

50. Ly Q, Merinov BV, Xiao H, Goddard WA, Yu TH. The oxygen reduction reaction on graphene from quantum mechanics: comparing armchair and zigzag carbon edges. J Phys Chem C. $2017 ; 121(39): 24408-17$.
51. Li M, Zhang L, Xu Q, Niu J, Xia Z. N-doped graphene as catalysts for oxygen reduction and oxygen evolution reactions: theoretical considerations. J Catal. 2014;314:66-72.

52. Shen A, Zou Y, Wang Q, Dryfe RAW, Huang X, Dou S, et al. Oxygen reduction reaction in a droplet on graphite: direct evidence that the edge is more active than the basal plane. Angew Chem Int Ed. 2014;53(40):10804-8.

53. Ortiz-Medina J, Wang Z, Cruz-Silva R, Morelos-Gomez A, Wang F, Yao X, et al. Defect Engineering and Surface Functionalization of Nanocarbons for Metal-Free Catalysis. Adv Mater. 2019;31(13):1805717. 